\title{
Update on Patient Management in Hepatic Surgery
}

\section{Badr Serji*}

Department of Surgery, Mohammed the First University, Oujda, Morocco

\begin{abstract}
In the era of modern medicine, hepatic surgery knew radical changes allowing improvement in morbidity and mortality. Those results were possible due to the improvement made in each step of the management of the patient. Preoperatively, many techniques (such as volumetry, hepato-biliary scintigraphy, magnetic resonance relaxometry...) allow now the assessment of the volume and liver function, which is now a standard of care. In operation room, the combination of different techniques of clamping and new devices of hemostasis contributes to improve blood loss control. In general, morbi-mortality in hepatic surgery is related to the risk of hemorrhage, biliary fistula and postoperative liver failure (PHLF). In this article we propose to review recent literature concerning new techniques in the prevention of those 3 situations.
\end{abstract}

Keywords: Patient management; Hepatic surgery; Update

\section{Introduction}

Postoperative liver failure is actually the first cause of morbidity and mortality after hepatectomy [1-3]. Many methods were used trying to prevent and predict the occurrence of PHLF by calculating the future remnant liver volume [4,5], evaluating the hepatic function [6] and assessing the degree of an underlying liver injury using invasive and non-invasive methods [7-9].

\section{Assessment of liver volume}

Future remnant liver volume is one of the most important parameter to evaluate before going on hepatic major resection. Since it's first use and description [9], many publications tried to assess the appropriate remnant liver volume after hepatectomy as a ratio between the future remnant liver (FRL) and total liver volume (TLV) $[10,11]$. Taking in consideration that the future remnant liver volume must be correlated to the metabolic needs of the body of the patient, and the possible misdiagnosed lesions in imaging, Vauthey et al. described a new formula to define total remnant liver volume according to body surface area or body weight. The formula showed a good correlation and prediction for the minimum required liver volume in western adult patients [12]. However it had some limitations especially in situations with repeat hepatectomy where the actual total liver volume is lower than the initial total liver volume. Truand et al. proposed a new method based on the remnant liver volume to body weight ratio wish showed a good ability to predict post-operative risk after major hepatectomy in non-cirrhotic liver with a cut off at $0.5 \%$ [13]. These 2 formulas are widely accepted and used in western countries for non-cirrhotic liver $[12,13]$. However, evaluating liver remnant volume is not enough, especially when underlying liver injuries are present (fibrosis, cirrhosis, chronic hepatitis...). Attention should be paid to liver function too.

\section{Assessment of liver function}

Many routine biological tests were used trying to assess liver function and to predict morbidity and mortality after hepatectomy [14], but none of them had enough sensitivity or specificity especially with the extension of indications of major hepatectomy in patients with chronic liver injury. Those tests were combined into scores like Child-Pugh and MELD score for more accuracy in predicting morbidity and mortality after hepatic resection [15]. Dynamic tests showed more accuracy in predicting PHLF. The Indocyanine green clearance is one of the oldest [16] and still up to date dynamic test, which allow a good selection of patients with a good hepatic function [17]. Hepatobiliary scintigraphy using marked tracer like Technetium99m-diethylenetriamine-pentaacetic acid-galactosylhuman serum albumin (99mTc-GSA), showed also a good correlation predicting post-operative complications and more accuracy when compared to CT volumetry alone [18]. Another dynamic test called LIMAX (Test For Maximal Liver function), based on a respiratory test, which quantifies the metabolism of $\mathrm{C}$-methacetine in the liver without any influence, by a drug uptake or the presence of cholestasis, showed a good correlation with the occurrence of PHLF especially in first day after hepatectomy [19]. Others dynamic tests were described based on the metabolism of some substances like lignocaine or galactose but showed some limits like interference with drug uptake or time consuming technique [20,21]. Recently new studies combined techniques for estimation of both liver volume (based on MRI) and liver function (using ICG retention or hepato-biliary scintigraphy) $[22,23]$. Results showed good correlation in predicting PHLF.

\section{Assessment of fibrosis and cirrhosis}

Existence of chronic hepatic injury like advanced fibrosis or cirrhosis is a determinant factor that can lead to PHLF after major hepatic resection. Liver biopsy is the gold standard for the evaluation of the degree of fibrosis $[24,25]$. However it can show some limits due to sampling related to inter operator variability [26], risk of tumor seeding when associated to biopsy for lesion diagnosis [27] and finally because it's invasive even through a trans jugular access with less morbidity [28]. Serum biomarkers are used and give moderate estimation of liver fibrosis [29] comparable to given information by liver biopsy in main chronic liver disease. They are based on the use of blood test of some liver markers such as ALAT, ASAT, haptoglobine and bilirubin. Those markers are combined into scores that shows a good predictive value of liver fibrosis. The Asian-Pacific Association suggested Fibro test to be accurate for the Study of the Liver on its 2016 guideline beside AST platelet ratio index (APRI). The last one is especially useful in resourcelimited conditions [26]. Improvement in imaging technique and recent publications suggest that magnetic resonance elastography [30] and Acoustic radiation force impulse imaging ARFI [30] allows nowadays to perform a good assessment of liver fibrosis with high sensitivity and specificity.

*Corresponding author: Badr Serji, Surgery Department, Oncological Center Hassan II, Medical school, Mohammed the First University, Oujda, Morocco, Tel: +212661057057; E-mail: badr.serji@hotmail.fr

Received March 15, 2017; Accepted April 07, 2017; Published April 15, 2017

Citation: Serji B (2017) Update on Patient Management in Hepatic Surgery. Surgery Curr Res 7: 292. doi: 10.4172/2161-1076.1000292

Copyright: @ 2017 Serji B. This is an open-access article distributed under the terms of the Creative Commons Attribution License, which permits unrestricted use, distribution, and reproduction in any medium, provided the original author and source are credited. 


\section{Procedures to prevent liver failure}

To prevent liver failure, portal vein embolization (PVE) became the standard of care to increase liver volume when major hepatectomy is planned under normal liver for a FRL less than $20 \%$ of TLV, or less than $30 \%$ in case of liver injury and less than $40 \%$ in patients with well compensated fibrosis or cirrhosis [31]. Resection is generally accepted when FRL reached 20 to $40 \%$ of TLV according to the presence of liver disease [32]. Allard et al. advises to assess portal vein pressure per operatively to prevent liver failure, they propose to module portal vein pressure when it exceeds $20 \mathrm{mmHg}$ [33]. In last few years a new technique associating liver partition and portal vein ligation for staged hepatectomy (ALPPS) was described to allow rapid grow of FRL [34]. It consists on realizing a liver partition and portal vein ligation in the first stage, control sufficient future remnant liver hypertrophy from day 7 after first stage and perform the second stage which consist on liver resection. This technique drew big interest in the community of HBP surgeons with many controversial opinions justifying the creation of a registry of ALPPS and first results was reported showing significant morbidity (29\%) and mortality (7\%) especially in the second stage where two third of mortality were related to liver failure [35]. Therefore an expert meeting was organized in Hamburg Germany in February 2015 and brought eight recommendations trying to identify adapted indication for ALPPS and to reduce morbidity and mortality [36]. In the same field a modified ALPPS was described in few cases and consists of minimizing liver partition, avoiding liver mobilization and no hilar dissection in the first stage. According to authors this will contribute to report the aggressive part of the procedure to the second stage. In four cases reported, patients achieved the two stages and were discharged with no liver failure or major complications [37].

\section{Prevention of blood loss}

Blood loss with operative transfusion are main factors associated with mortality after hepatectomy $[38,39]$. There are many techniques to decrease blood loss during hepatic resection. Total or partial hepatic inflow occlusion, use of topical agents, use of new devices of hemostasis or modulation of physiologic variable manipulation. A review published on 2014, including prospective studies for the evaluation of different methods of minimizing blood loss, found that low central venous pressure associated with total inflow occlusion up to $120 \mathrm{~min}$ or intermittent inflow occlusion up to 120 min were associated with reduction of blood loss especially in major hepatectomy. Inferior vena cava occlusion was not advised and was associated with increased risk of pulmonary embolism [40]. A Cochrane review, published in 2009, included seven trials randomizing 556 patients and compared different methods for parenchymal transection. The conclusion showed that clamp-crush technique induces less blood loss comparing to radiofrequency dissecting sealer with no difference in blood transfusion, intensive therapy unit stay or hospital stay. The blood transfusion requirements were lower in the clamp-crush technique than CUSA and hydrojet. There was no significant difference in the mortality, morbidity, markers of liver parenchymal injury or liver dysfunction, intensive therapy unit stay or hospital stay in the other comparisons including Cavitron ultrasound, surgical aspirator, sharp dissection and hydrojet. Clamp-crush technique was two to six times cheaper than the other methods depending upon the number of surgeries performed each year [41]. Gotohda et al. [42] conducted a multicentric randomized controlled trial to show the non-inferiority of energy devices in liver transection. They demonstrated that hepatectomy with energy device is not inferior to that without energy device in terms of blood loss. It even shortens the liver transection time and reduces the incidence of postoperative bile leakage. Topical agents are widely used too to ensure hemostasis during hepatectomy. A meta-analysis including randomized clinical trials, large retrospective cohort studies and case control studies was published and found no significant difference when using a carrierbound fibrin sealant (compared to the use of a product based on a human or animal matrix only or without using any hemostatic agent) in term of blood transfusion, risk of deep collections and bile leak (OR $0.75 ; \mathrm{p}=0.25)$, (OR 0.72; $\mathrm{p}=0.52),(\mathrm{OR} 0.74 ; \mathrm{p}=0.30$ ) respectively. There was only difference in time to obtain hemostasis (mean difference -2.33 $\min ; \mathrm{p}=0.00001$ ) [43].

\section{Prevention of bile leak}

Biliary fistula remains on of the common sources for morbidity and mortality after hepatectomy [44]. However different definitions have been proposed to define it $[45,46]$. A prospective evaluation of the bile leak definition proposed by the International Study Group for Liver Surgery showed that it is a robust definition with a good correlation between proposed grading and clinical severity [47]. They found in the same study that the use or not of routine drainage didn't impact the rate of post-operative bile leak [47]. Many tests were described to identify and prevent biliary fistula such as perioperative cholangiography, dye injection like Indocyanine green, saline injection and compress test [48-51]. In 2008, a new test consisting on the injection of a white fat emulsion to detect per operatively a bile leak [52]. This test was studied in a meta-analysis to investigate its value [53]. In the included studies the white test allowed a significant reduction of post-operative biliary leakage [OR: 0.3 (95\% CI: 0.14, 0.63), $\mathrm{p}=0.002$ ] and led to a significant higher intraoperative detection of biliary leakages [OR: 0.03 (95\%CI: 0.02, 0.07), $\mathrm{p}<0.00001]$ [54].

\section{Drainage}

Abdominal drainage after hepatic resection remains controversial and did not allow to reduce rate of postoperative complications [54]. Actual and recent data support no need of routine abdominal drainage after uncomplicated liver resections [55]. However the question remains open for major and complicated hepatectomy.

\section{Discussion}

Since the first laparoscopic hepatectomy performed in 1992 [56], laparoscopic liver resection knew wide diffusion through the community of HBP surgeons leading to the publications of multiple series [57-59]. From which the consensus conference in Louisville in 2008 that discusses specific field like indications for surgery, patient selection, surgical techniques, complications, patient safety, and surgeons training [60]. Laparoscopic liver resections were defined into pure laparoscopy, hand assisted laparoscopy, and the hybrid technique. Laparoscopic resections are reserved for patients with solitary lesions, $5 \mathrm{~cm}$ or less, located in liver segments 2 to 6 . Left lateral sectionectomy should be considered standard practice [60]. Major liver resections should be reserved for experienced centers. Indications for benign hepatic lesions should not be extended simply because the surgery can be done laparoscopically. Conversion should be considered prudent practice rather than failure [60]. After this consensus conference, laparoscopic liver resection knew a huge diffusion amount surgeon in different countries [61]. A second consensus conference was held in Morioka on 2014 [62] and gave new recommendations based on literature review and opinions experts, and following IDEAL methodology considering laparoscopic liver resection as an innovation in hepatic surgery [63]. Minor hepatectomy is considered as standard of care but still in assessment (IDEAL 3). Major hepatectomy are 
considered an innovative technique and classed (IDEAL 2b). Beginning in laparoscopic liver resection needs expertise in both open liver surgery and general laparoscopic surgery. Hand assisted and hybrid technique may be useful in minimizing conversions initially. $\mathrm{A} \mathrm{CO}_{2}$ pneumo peritoneum between 12 and $15 \mathrm{mmHg}$ with low central venous pressure allow a good control of bleeding. Parenchymal transection and energy devices are left to surgeon discretion. They conclude that there is a need to standardize the laparoscopic resection for hepatocellular carcinoma and liver metastasis like for open resections especially for major hepatectomy [63].

\section{Conclusion}

Now-a-days hepatic surgery knows huge changes allowing improvement in patient and disease management. Innovations and novel technique are in perpetual development. Hepatic surgeons must remain up to date to offer to their patients the best chance for cure that they deserve.

\section{References}

1. Yang T, Zhang J, Lu JH, Yang GS, Wu MC, et al. (2011) Risk factors influencing postoperative outcomes of major hepatic resection of hepatocellular carcinoma for patients with underlying liver diseases. World J Surg 35: 2073-2082.

2. Kusano T, Sasaki A, Kai S, Endo Y, Iwaki K, et al. (2009) Predictors and prognostic significance of operative complications in patients with hepatocellular carcinoma who underwent hepatic resection. Eur J Surg Oncol 35: 1179-1185.

3. Rahbari NN, Reissfelder C, Koch M, Elbers H, Striebel F, et al. (2011) The predictive value of postoperative clinical risk scores for outcome after hepatic resection: A validation analysis in 807 patients. Ann Surg Oncol 18: 3640-3649.

4. Okamota E, Kyo A, Yamanaka N, Tanaka N, Kuwata K (1984) Prediction of the safe limits of hepatectomy by combined volumetric and functional measurements in patients with impaired hepatic function. Surgery 95: 586-592.

5. Yamanaka N, Okamoto E, Kuwata K, Tanaka N (1984) A multiple regression equation for prediction of posthepatectomy liver failure. Ann Surg 200: 658-663.

6. Torzilli G, Makuuchi M, Inoue K, Takayama T, Sakamoto Y, et al. (1999) Nomortality liver resection for hepatocellular carcinoma in cirrhotic and noncirrhotic patients: is there a way? A prospective analysis of our approach. Arch Surg 134: 984-992.

7. Judmaier G, Prior C, Klimpfinger M, Bernklau E, Vogel W, et al. (1989) Is percutaneous liver biopsy using the 'Tru-Cut' '(Travenol) needle superior to Menghini puncture? Z Gastroenterol 27: 657-661.

8. van Leeuwen DJ, Wilson L, Crowe DR (1995) Liver biopsy in the mid 1990s: questions and answers. Semin Liver Dis 15: 340-359.

9. Heymsfield SB, Fulenwider T, Nordlinger B, Barlow R, Sones P (1979) Accurate measurement of liver, kidney, and spleen volume and mass by computerized axial tomography. Ann Intern Med 90: 185-187.

10. Higashiyama H, Yamaguchi T, Mori K, Nakano Y, Yokoyama T, et al. (1993) Graft size assessment by preoperative computed tomography in living related partial liver transplantation. Br J Surg 80: 489-492.

11. Shoup M, Gonen M, D'Angelica M, Jarnagin WR, DeMatteo RP, et al. (2003) Volumetric analysis predicts hepatic dysfunction in patients undergoing major liver resection. J Gastrointest Surg 7: 325-330.

12. Vauthey JN, Abdalla EK, Doherty DA, Gertsch P, Fenstermacher MJ, et al. (2002) Body surface area and body weight predict total liver volume in Western adults. Liver Transpl 8: 233-240.

13. Truant S, Oberlin O, Sergent G, Lebuffe G, Gambiez L, et al. (2007) Remnant liver volume to body weight ratio > or $=0.5 \%$ : A new cut-off to estimate postoperative risks after extended resection in noncirrhotic liver. J Am Coll Surg 204: 22-33.

14. Zimmermann H, Reichen J (1998) Hepatectomy: Preoperative analysis of hepatic function and postoperative liver failure. Dig Surg 15: 1-11.

15. Huo T, Lee S, Lin H (2008) Selecting an optimal prognostic scoring system for liver cirrhosis: The model for end-stage liver disease and beyond. Liver Int 28 : 606-613.
16. Matsumata T, Kanematsu T, Yoshida Y, Furuta T, Yanaga K, et al. (1987) The indocyanine green test enables prediction of postoperative complications after hepatic resection. World J Surg 11: 678-681.

17. Imamura H, Sano K, Sugawara Y, Kokudo N, Makuuchi M (2005) Assessment of hepatic reserve for indication of hepatic resection: decision tree incorporating indocyanine green test. J Hepatobiliary Pancreat Surg 12: 16-22.

18. Dinanat S, de Graaf W, Verwer BJ, Bennink RJ, van Lienden KP, et al (2007) Risk assessment of post-hepatectomy liver failure using hepatobiliary scintigraphy and CT volumetry. J Nucl Med 48: 685-692.

19. Stockmann M, Lock JF, Riecke B, Heyne K, Martus P, et al. (2009) Prediction of postoperative outcome after hepatectomy with a new bedside test for maximal liver function capacity. Ann Surg 250: 119-125

20. Bargetzi MJ, Aoyama T, Gonzalez FJ, MeyerUA (1989) Lidocainemetabolism inhuman liver microsomes by cytochrome P450IIIA. Clin Pharmacol Ther 46 521.

21. Merckel C, Gatta Z, Zoli M, Bolognesi M, Angeli P, et al. (1991) Prognostic value of galactose elimination capacity, aminopyrine breath test and ICG clearance in patients with cirrhosis. Comparison with the Pugh score. Digest Dis Sci 36 1197-1203.

22. Haimerl M, Schlabeck M, Verloh N, Zeman F, Fellner C, et al. (2016) Volumeassisted estimation of liver function based on Gd-EOB-DTPA-enhanced MR relaxometry. Eur Radiol 26: 1125-1133.

23. Chapelle T, Op De Beeck B, Huyghe I, Francque S, Driessen A, et al. (2016) Future remnant liver function estimated by combining liver volumetry on magnetic resonance imaging with total liver function on (99m) Tc-mebrofenin hepatobiliary scintigraphy: can this tool predict post-hepatectomy liver failure? HPB (Oxford) 18: 494-503.

24. Grigorescu M (2006) Noninvasive biochemical markers of liver fibrosis. J Gastrointestin Liver Dis 15: 149-159.

25. Kalambokis G, Manousou P, Vibhakorn S, Marelli L, Cholongitas E, et al. (2007) Transjugular liver biopsy: indications, adequacy, quality of specimens, and complications: A systematic review. J Hepatol 47: 284-294.

26. Shiha G, Ibrahim A, Helmy A, Sarin SK, Omata M, et al. (2016) Asian-Pacific Association for the Study of the Liver (APASL) consensus guidelines on invasive and non-invasive assessment of hepatic fibrosis: A 2016 update. Hepatol Int 11: 1-30.

27. Bialecki ES, Ezenekwe AM, Brunt EM, Collins BT, Ponder TB, et al. (2006) Comparison of liver biopsy and noninvasive methods for diagnosis of hepatocellular carcinoma. Clin Gastroenterol Hepatol 4: 361-368.

28. Beckmann MG, Bahr MJ, Hadem J, Bredt M, Wedemeyer H, et al. (2009) Clinical relevance of transjugular liver biopsy in comparison with percutaneous and laparoscopic liver biopsy. Gastroenterol Res Pract.

29. Poynard T, Morra R, Ingiliz P, Imbert-Bismut F, Thabut D, et al. (2008) Biomarkers of liver fibrosis. Adv Clin Chem 46: 131-160.

30. Wang QB, Zhu H, Liu HL, Zhang B (2012) Performance of magnetic resonance elastography and diffusion-weighted imaging for the staging of hepatic fibrosis: A meta-analysis. Hepatology 56: 239-247.

31. Friedrich-Rust M, Nierhoff J, Lupsor M, Sporea I, Fierbinteanu- Braticevici C et al. (2012) Performance of acoustic radiation force impulse imaging for the staging of liver fibrosis: a pooled meta-analysis. J Viral Hepat 19: 212-219.

32. Vauthey JN, Dixon E, Abdalla EK, Helton WS, Pawlik TM, et al. (2010) Pretreatment assessment of hepatocellular carcinoma: expert consensus statement. HPB (Oxford) 12: 289-299.

33. Allard MA, Adam R, Bucur PO, Termos S, Cunha AS, et al. (2013) Posthepatectomy portal vein pressure predicts liver failure and mortality after major liver resection on noncirrhotic liver. Ann Surg 258: 822-829.

34. Schnitzbauer AA, Lang SA, Goessmann H, Nadalin S, Baumgart J, et al. (2012) Right portal vein ligation combined with in situ splitting induces rapid left lateral liver lobe hypertrophy enabling 2-staged extended right hepatic resection in small-for-size settings. Ann Surg 255: 405-414.

35. Schadde E, Ardiles V, Robles-Campos R, Malago M, Machado M , et al. (2014) Early survival and safety of ALPPS: first report of the International ALPPS Registry. Ann Surg 260: 829-836.

36. Oldhafer KJ, Stavrou GA, van Gulik TM, Core Group (2016) ALPPS -where do we stand, where do we go? Eight Recommendations From the First 
International Expert Meeting. Ann Surg 263: 839-841.

37. de Santibañes E, Alvarez FA, Ardiles V, Pekolj J, de Santibañes M (2016) Inverting the ALPPS paradigm by minimizing first stage impact: the MiniALPPS technique. Langenbecks Arch Surg 401: 557-63.

38. Jarnagin WR, Gonen M, Fong Y, DeMatteo RP, Ben-Porat L, et al. (2002) Improvement in perioperative outcome after hepatic resection: Analysis of 1,803 consecutive cases over the past decade. Ann Surg 236: 397- 407.

39. Fan ST, Mau Lo C, Poon RT, Yeung C, Leung Liu C (2011) Continuous improvement of survival outcomes of resection of hepatocellular carcinoma: A 20-year experience. Ann Surg 253: 745-758.

40. Huntington JT, Royall NA, Schmidt CR (2014) Minimizing blood loss during hepatectomy: A literature review. J Surg Oncol 109: 81-88.

41. Gurusamy KS, Pamecha V, Sharma D, Davidson BR (2009) Techniques for liver parenchymal transection in liver resection. Cochrane Database Syst Rev.

42. Gotohda N, Yamanaka T, Saiura A, Uesaka K, Hashimoto M, et al. (2015) Impact of energy devices during liver parenchymal transection: A multicenter randomized controlled trial. World J Surg 39: 1543-1549.

43. Brustia R, Granger B, Scatton O (2016) An update on topical haemostatic agents in liver surgery: Systematic review and meta analysis. J Hepatobiliary Pancreat Sci 23: 609-621.

44. Lo CM, Fan ST, Liu CL, Lai EC, Wong J (1998) Biliary complications after hepatic resection: Risk factors, management, and outcome. Arch Surg 133: 156-161.

45. Torzilli G, Olivari N, Del Fabbro D, Gambetti A, Leoni P, et al. (2005) Bilirubin level fluctuation in drain discharge after hepatectomies justifies longterm drain maintenance. Hepatogastroenterology 52: 1206-1210.

46. Koch M, Garden OJ, Padbury R, Rahbari NN, Adam, et al. (2011) Bile leakage after hepatobiliary and pancreatic surgery: A definition and grading of severity by the International Study Group of Liver Surgery. Surgery 149: 680-688.

47. Brooke-Smith M, Figueras J, Ullah S, Rees M, Vauthey JN, et al. (2015) Prospective evaluation of the International Study Group for Liver Surgery definition of bile leak after a liver resection and the role of routine operative drainage: an international multicentre study. HPB (Oxford) 17: 46-51.

48. Kubo S, Sakai K, Kinoshita H, Hirohashi K (1986) Intraoperative cholangiography using a balloon catheter in liver surgery. World J Surg 10: 844-849.

49. Noun R, Singlant JD, Belghiti J (1996) A practical method for quick assessment of bile duct patency during hepatic resection. J Am Coll Surg 183: 77-78.

50. Suehiro T, Shimada M, Kishikawa K, Shimura T, Soejima Y, et al. (2005) In situ dye injection bile leakage test of the graft in living donor liver transplantation.
Transplantation 80: 1398-1401.

51. Kaibori M, Ishizaki M, Matsui K, Kwon AH (2011) Intraoperative indocyanine green fluorescent imaging for prevention of bile leakage after hepatic resection Surgery 150: 91-98.

52. Nadalin S, Li J, Lang H, Sotiropoulos GC, Schaffer R, et al. (2008) The White test: A new dye test for intraoperative detection of bile leakage during major liver resection. Arch Surg 143: 402-044.

53. Linke R, Ulrich F, Bechstein WO, Schnitzbauer AA (2015) The White-test helps to reduce biliary leakage in liver resection: A systematic review and metaanalysis. Ann Hepatol 14: 161-167.

54. Gurusamy KS, Samraj K, Davidson BR (2007) Routine abdominal drainage for uncomplicated liver resection. Cochrane Database Syst Rev.

55. Gavriilidis P, Hidalgo E, de'Angelis N, Lodge P, Azoulay D (2017) Re-appraisa of prophylactic drainage in uncomplicated liver resections: A systematic review and meta-analysis. HPB (Oxford) 19: 16-20.

56. Gagner M, Rheault M, Dubuc J (1992) Laparoscopic partial hepatectomy for liver tumor. Surg Endosc 6: 99

57. Kaneko H, Takagi S, Shiba T (1996) Laparoscopic partial hepatectomy and left lateral segmentectomy: Technique and results of a clinical series. Surgery120: $468-475$.

58. Dagher I, Proske JM, Carloni A, Richa H, Tranchart H, et al. (2007) Laparoscopic liver resection: Results for 70 patients. Surg Endosc 21: 619-624.

59. Cherqui D, Soubrane O, Husson E, Barshasz E, Vignaux O, et al. (2002) Laparoscopic living donor hepatectomy for liver transplantation in children. Lancet 359: 392-396.

60. Buell JF, Cherqui D, Geller DA, O'Rourke N, lannitti D et al. (2009) World Consensus Conference on Laparoscopic Surgery. The international position on laparoscopic liver surgery: The Louisville Statement, 2008. Ann Surg 250: 825-830.

61. Hibi T, Cherqui D, Geller DA, Itano O, Kitagawa Y, et al. (2014) International Survey on Technical Aspects of Laparoscopic Liver Resection: A web-based study on the global diffusion of laparoscopic liver surgery prior to the $2 \mathrm{nd}$ International Consensus Conference on Laparoscopic Liver Resection in Iwate, Japan. J Hepatobiliary Pancreat Sci 21: 737-744.

62. Wakabayashi G, Cherqui D, Geller DA, Buell JF, Kaneko H et al. (2015) Recommendations for laparoscopic liver resection: A report from the second international consensus conference held in Morioka. Ann Surg 261: 619-629.

63. McCulloch P, Altman DG, Campbell WB, Flum DR, Glasziou P, et al. (2009) No surgical innovation without evaluation: the IDEAL recommendations. Lancet 26: 1105-1112. 